\title{
A REALIDADE DO USO DAS TIC'S NA SALA DE AULA EM UMA ESCOLA DE SÃO FRANCISCO DE PAULA, RIO GRANDE DO SUL, BRASIL.
}

\author{
Roberta Medeiros dos Santos - rms.medeiros@uol.com.br - SEDUC/RS \\ Luciano Andreatta-da-Costa - luciano@uergs.edu.br-Uergs/ Liberato \\ Maria Altina Silva Ramos - altina@ie.uminho.pt - UMINHO
}

\begin{abstract}
Resumo: Este artigo tem como objetivo analisar como as Tecnologias de Informação e Comunicação (TIC's) são integrados com o processo de ensino da matemática em três grupos de terceiro ano da Escola Politécnica da Rede Estadual de São Francisco de Paula, Rio Grande do Sul, Brasil, no período Maio-junho de 2015. O seu objetivo geral é analisar se o uso da tecnologia é parte do ensino da matemática. Nesta pesquisa foi adotado o Survey como desenho metodológico, a partir de um questionário composto de perguntas abertas e fechadas. Os resultados mostraram que esta instituição não tem os recursos necessários para a integração das TIC's nas salas de aula de matemática e, portanto, o uso dessas tecnologias não são parte do ensino da matemática. No entanto, pode-se observar que iniciativas como a pesquisa que levou a este artigo é extremamente rica para promover uma abordagem da comunidade escolar com o tema das TIC's e seu uso na educação.
\end{abstract}

Palavra-chave: Tecnologias de Informação e Comunicação - TIC's, Educação Matemática, Formação de professores.

\section{THE USE OF ICT IN THE CLASSROOM IN A SCHOOL OF SAN FRANCISCO DE PAULA, RIO GRANDE DO SUL, BRAZIL.}

\begin{abstract}
This paper aims to analyze how Information and communication technologies (ICT) are integrated with the mathematics teaching process into three groups of third year of the Polytechnic School of the State System of San Francisco de Paula, Rio Grande do Sul, Brazil, in the period May-June 2015. The overall objective is to analyze the use of technology is part of mathematics teaching. This research adopted the Survey as methodological design, from a questionnaire consisting of open and closed questions. The results showed that this institution does not have the necessary resources for the integration of ICT in mathematics classrooms and therefore the use of these technologies are not part of mathematics teaching. However, you can also see that initiatives such as the research that led to this article is extremely rich to promote the school community approach to the subject of TIC's and its use in education.
\end{abstract}

Key-words: Information and Communication Technologies - ICT`s, Mathematic Education, Teacher Education.

\section{Introdução}

Este artigo busca analisar como as tecnologias estão agregadas ao processo do ensino da Matemática nas três turmas do Terceiro Ano do Ensino Médio Politécnico na Rede Estadual de Ensino, do município de São Francisco de Paula, Rio Grande do Sul, Brasil de acordo com as perspectivas de alunos, professores e gestores.

É preciso lembrar que tecnologia é tudo aquilo que o homem criou para facilitar a sua rotina, ou seja, surgiu de sua necessidade diária. A tecnologia é tudo o que gera resultados melhores e mais rápidos dos que já haviam sido gerados até o momento. 
Quando estas tecnologias são usadas para fins educativos, nomeadamente para apoiar e melhorar a aprendizagem dos alunos e desenvolver ambientes de aprendizagem, podemos considerar as TIC's (Tecnologias da Informação e Comunicação) como um subdomínio da TE (Tecnologia Educativa), como afirma Miranda (2007).

Segundo Belloni (2009), as tecnologias estão presentes no mundo modificando tudo ao seu redor (social e economicamente), cabendo às escolas integrá-las ao seu currículo para poder tirar um melhor proveito delas, podendo assim contribuir para um maior aumento de autonomia e de eficiência no processo de ensino aprendizagem do aluno. Tanto Belloni (2005) como Masetto e Behrens (2000) acreditam que os recursos tecnológicos não se justificam por si mesmos, mas sim pelos objetivos que se pretenda que elas alcancem na aprendizagem. Para Bastos e Ramos (2005) o uso das tecnologias faz com que o aluno contribua de forma ativa para sua aprendizagem desenvolvendo um pensamento profundo e crítico para interpretar e refletir.

Nesse contexto, "o acesso ao conhecimento e, em especial, à rede informatizada, desafia o docente a buscar nova metodologia para atender às exigências da sociedade" (Moran, Behrens \& Masetto, 2011, p. 71), pois no momento em que se adere às novas tecnologias no ambiente escolar, esta situação tende a exigir mudanças tanto na técnica como na forma de ver o ensino.

\section{Professores e alunos na era digital}

Moran (2007) enfatiza que para ocorrer uma mudança educacional é preciso que existam professores bem preparados, que tenham liberdade para suas escolhas. Segundo o mesmo autor não adianta o professor saber o conteúdo, mas não saber como trabalhar com os alunos.

A transmissão de informação é a tarefa mais fácil e em que as tecnologias podem ajudar o professor a facilitar o seu trabalho. Um simples CD-ROM contém toda a Enciclopédia Britânica, que também pode ser acessada pela Internet. $\mathrm{O}$ aluno nem precisa ir à escola para buscar as informações. Mas, para interpretá-las, relacioná-las, hierarquizá-las, contextualizá-las, só as tecnologias não serão suficientes. O professor ajudará a questionar, a procurar novos ângulos, a relativizar dados, a tirar conclusões. (MORAN, 2007, p. 52)

Sendo assim, o professor passará a ter uma nova função: deixará de ser o transmissor do conhecimento para ser um mediador da aprendizagem.

Para Moran (2007) "o foco para a mudança é desenvolver alunos criativos, inovadores, corajosos. Alunos e professores que busquem soluções novas, diferentes que arrisquem mais, que relacionem mais, que saiam do previsível, do padrão".

Conforme afirma Dowbor:

O fato de se introduzir novas tecnologias no campo educacional modifica profundamente a função do educando, em particular do adulto, que deve se tornar sujeito da própria formação, frente à diferenciação e riqueza dos espaços de conhecimento nos quais deverá participar. A educação vista neste prisma tende a se tornar de certa forma orientada pela demanda, sendo que construir o seu próprio universo de conhecimento passa a ser uma condição central da 
inserção social das pessoas. (DOWBOR, 2013, p. 8)

\section{Tecnologias na Matemática}

As tecnologias fazem parte das atividades rotineiras dos alunos e precisam estar inseridas na aprendizagem de Matemática, como em qualquer outra área curricular. É preciso utilizar "a Matemática como ferramenta para entender as tecnologias, e a tecnologia como ferramenta para entender a Matemática” (BRASIL, 2008, p. 87). O grande desafio da educação é perceber que podemos utilizar as tecnologias de uma forma frequente e significativa para o aluno. Tanto no uso das planilhas eletrônicas, que são programas de computador que servem para manipular tabelas, quanto no uso da calculadora, é preciso a utilização do conhecimento Matemático. Não é possível chegar ao resultado se não souber os passos matemáticos necessários para isso.

Existem softwares específicos para a aprendizagem de alguns conteúdos matemáticos. A partir do seu uso, os alunos podem construir e reforçar conceitos, estimular o raciocínio lógico e criar estratégias de resolução. Podem ser utilizadas também simulações para o ensino de ciências e matemática, como os seguintes exemplos: (i) Universidade do Colorado https://phet.colorado.edu/pt_BR/); (ii) Banco Internacional de Objetos Educacionais (http://objetoseducacionais2.mec.gov.br/); (iii) RIVED (http://rived.mec.gov.br/).

Neste contexto, o professor passa a desempenhar um papel de mediador, ou seja, deixa de ser o centro da aprendizagem onde o foco é ensinar a reproduzir conhecimento e passa a se preocupar com o "aprender a aprender", criando um ambiente favorável que possibilite a investigação e a construção do conhecimento por parte do aluno.

\section{Metodologia}

Este artigo possui um plano de investigação descritivo, pois seu objetivo foi estudar as características de um grupo específico. Segundo Gil (2010), "as pesquisas descritivas têm como objetivo a descrição das características de determinada população. Podem ser elaboradas também com a finalidade de identificar possíveis relações entre variáveis".

Ele tem como procedimento de investigação o survey, pois é um estudo feito a partir de um questionamento ao qual procuramos responder a partir de dados obtidos junto de uma amostra de sujeitos.

A amostra foi selecionada por conveniência para podermos fazer um estudo específico com as turmas do último ano do Ensino Médio Politécnico. Trata-se de uma amostra de conveniência por se tratar de um grupo já constituído (turmas do $3^{\circ}$ ano do Ensino Médio Politécnico) a que a investigadora principal tem fácil acesso, como afirma Schutt (apud Coutinho, 2013).

O instrumento utilizado para a coleta de dados foi o questionário constituído por questões abertas e fechadas. As questões fechadas destinavam-se aos dados pessoais e algumas informações específicas da escola, já as abertas destinavam-se as opiniões e visões dos pesquisados.

As questões fechadas receberam um tratamento estatístico, elaborando-se tabelas e gráficos com os resultados gerados.

Já as questões abertas foram analisadas a partir da análise de conteúdo tendo-se identificado categorias que são apresentadas em um quadro para melhor representação dos resultados 


\section{Análise e discussão dos dados}

Os questionários foram entregues para noventa (90) pessoas: sete (7) pessoas da equipe diretiva; quatro (4) professores de Matemática e setenta e nove (79) alunos do Ensino Médio Politécnico.

Todos os questionários destinados para a equipe diretiva foram devolvidos ao investigador. Entre os professores somente de um (1) não obtivemos devolução. A quantidade de questionários que retornou entre os alunos foi de trinta e seis (36), totalizando quarenta e seis (46) questionários devolvidos ao todo.

A partir destes questionários, fizemos a tabulação e a análise de seus resultados.

\section{Qual o perfil dos pesquisados?}

A equipe diretiva, desta escola, é composta de seis (6) mulheres e um (1) homem. Cinco (5) deles possuem entre 45 e 50 anos, um (1) entre 50 e 55 anos e, o outro, entre 60 e 65 anos. Entre eles, um (1) é diretor (a), três (3) vice-diretores(as) e, os outros três (3) coordenadores.

Quatro (4) destes profissionais atuam na área do magistério no período de 20 a 25 anos, um (1) deles de 15 a 20 anos, outro de 30 a 35 anos e, somente um deles, não respondeu.

Cinco (5) deles possuem como maior nível de formação acadêmica a especialização (sendo identificados dois (2) em Gestão Escolar e dois (2) em Gestão Educacional), um (1) possui, somente, a Licenciatura e o outro possui mestrado.

Entre os professores todos são mulheres. Duas (2) delas estão entre 30 e 35 anos e uma (1) entre 35 e 40 anos. Duas (2) delas trabalham entre 10 e 15 anos e uma (1) delas entre 15 e 20 anos.

As três (3) professoras são graduadas em Matemática e uma delas, também, em Letras Espanhol, sendo que todos possuem especialização.

Dos trinta e seis (36) alunos, quinze (15) são do sexo masculino e vinte e um (21) do sexo feminino. As faixas etárias predominantes são de dezesseis (16) anos $(44 \%)$ e dezessete (17) anos (42\%). O restante dos alunos possui 18 anos.

\section{Como está a formação em tecnologia educativa na escola?}

A maioria dos professores da equipe diretiva, quatro (4) pessoas, não possui nenhuma formação em tecnologia para educação, como mostra a Figura 1.

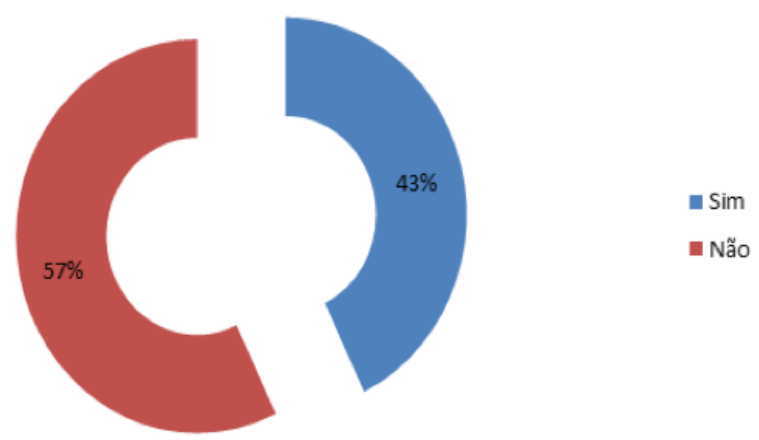

Figura 1 - Formação, da equipe diretiva, quanto ao uso das TIC na educação (Fonte: os autores)

Os quarenta e três por cento (43\%), que possuem qualificação, fizeram curso de extensão e oficinas onde um (1) deles trabalhou com a informática básica, com Ensino a 
Distância e mídias, o outro apenas com informática básica e, o terceiro, com tecnologia interativa, teleconferência, videoconferência, ambientes virtuais de aprendizagem (AVA) e software. Um (1) dos professores da equipe diretiva possui curso de aproximadamente sessenta (60) horas, o outro de aproximadamente, quatrocentas e oitenta (480) horas. Apenas um (1) dos profissionais não se referiu ao tempo aproximado destas formações.

Com os professores a realidade é um pouco diferente. Dois (2) deles já realizaram alguma formação nesta área, conforme mostra a Figura 2.

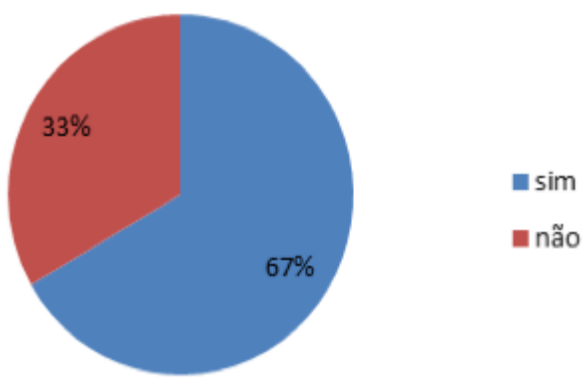

Figura 2 - Formação, dos professores, quanto ao uso das tecnologias na educação (Fonte: os autores)

Destes sessenta e sete por centro (67\%) que possuem formação, um deles se atualizou através de uma especialização de oitenta e oito (88) horas e o outro através de oficinas totalizando duzentas (200) horas.

$\mathrm{O}$ número de alunos que afirmaram se atualizarem frequentemente é bem significativo: setenta por cento $(70 \%)$. Vinte e dois por cento $(22 \%)$, afirmaram raramente se atualizarem e os oito por cento (8\%) restantes, disseram nunca se atualizarem como está sendo mostrado na Figura 3.

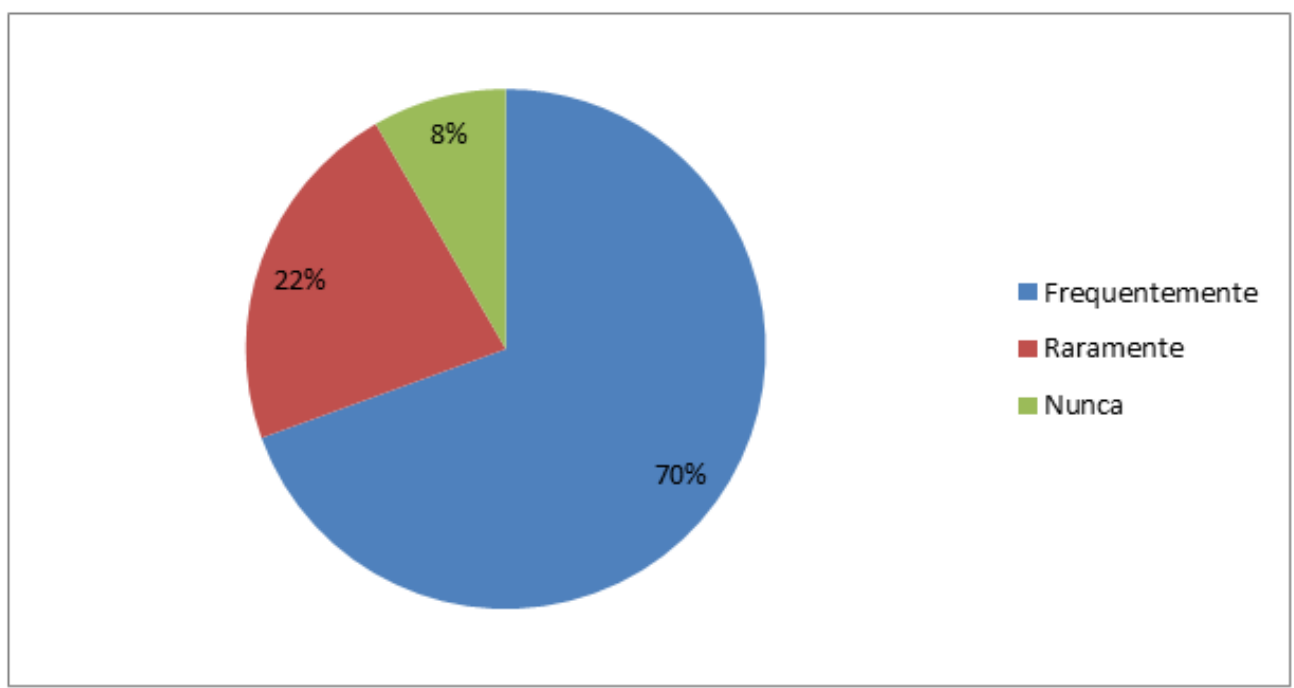

Figura 3 - Periodicidade de atualização dos alunos quanto as tecnologias (Fonte: os autores)

Ao comparar as três realidades percebe-se que os professores são os que mais possuem cursos de qualificações para a utilização das tecnologias educativas. Segundo esses profissionais, as qualificações ocorreram através de oficinas ou curso de especialização, em cursos de oitenta e oito (88) horas e em uma especialização com 
mais de duzentas (200) horas onde, em ambos, trabalharam com software educativo.

\section{A escola disponibiliza de Laboratório de Informática com recursos e professores disponíveis para o seu funcionamento?}

A visão da equipe diretiva - (57\%) - e dos alunos- (75\%) - coincide ao afirmar que o Laboratório de Informática está disponível na escola, mas que não é utilizado. Assim, como para todos os professores que afirmaram sua existência, mas não sua utilização.

A esse respeito Moran (2007) é bem categórico ao afirmar que:

Escolas não conectadas são escolas incompletas (mesmo quando didaticamente avançadas). Alunos sem acesso contínuo às redes digitais estão excluídos de uma parte importante da aprendizagem atual: do acesso à informação variada e disponível on-line, da pesquisa rápida em bases de dados, bibliotecas digitais, portais educacionais; da participação em comunidades de interesse, nos debates e publicações on-line, enfim, da variada oferta de serviços digitais. (MORAN, 2007, p. 9)

Partindo deste pressuposto, esta escola, atualmente, é uma escola incompleta, pois apesar de possuir uma sala de informática com diversos computadores falta o acesso constante a internet.

Está ocorrendo a integração para a utilização das TIC's entre os professores de Matemática com os das outras áreas?

Ao observar o Figura 4 fica evidente que não ocorre integração entre os professores de Matemática com os das outras áreas para a utilização das TIC.

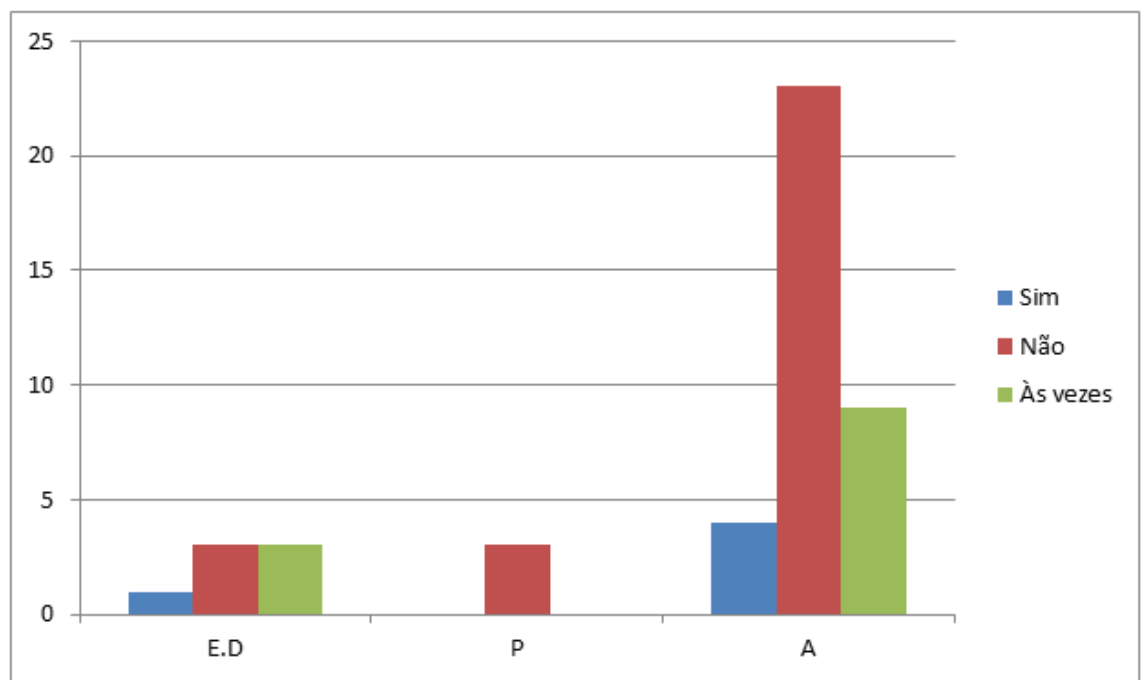

Figura 4 - Integração para a utilização das TIC entre os professores de Matemática com os das outras disciplinas na visão da equipe diretiva, professores e alunos (Fonte: os autores)

Tanto para os alunos quanto para os professores é clara essa não existência de integração entre as aulas de Matemática com as demais aulas. Já a equipe diretiva divide sua opinião em não existir e às vezes existir a integração entre os professores. 
Os professores da área de Matemática podem até ter conhecimento e trabalharem utilizando conceitos e conteúdos de outras áreas. No entanto, não realizam, com frequência, atividades envolvendo as TIC e os professores de outras áreas.

\section{Como está a freqüência do uso das tecnologias na escola e qual o software mais utilizado nas aulas de Matemática?}

Ao observar a Tabela 1 sobre a frequiência do uso das tecnologias na escola percebe-se que a moda tanto para a equipe diretiva, professores ou alunos é o "pouco freqüiente".

\begin{tabular}{l|l|l|l}
\hline & Equipediretiva & Professores & Alunos \\
\hline Inexistente & 1 & 1 & 6 \\
\hline Poucofrequente & 4 & 2 & 22 \\
\hline Frequente & 2 & 0 & 5 \\
\hline Muitofrequente & 0 & 0 & 3 \\
\hline Total & 7 & 3 & 36 \\
\hline
\end{tabular}

Tabela 1 - Visão da equipe diretiva, professores e alunos quanto a freqüência do uso das tecnologias na escola (A Autora)

\section{Quais as maiores dificuldades para o uso das tecnologias na sala de aula?}

Segundo a equipe diretiva, a maior dificuldade encontrada para a utilização das TIC's na escola é a capacitação dos professores (45\%); a falta de equipamentos ou máquinas atualizadas (22\%), e a proposta de ensino (22\%).

Os professores já percebem essas dificuldades de outra maneira. Para eles somente vinte por cento (20\%) é devido à falta de capacitação dos professores, quarenta por cento $(40 \%)$ devido a falta de equipamentos ou máquinas atualizadas e, com a mesma porcentagem, a falta de proposta de ensino adequada para o uso das tecnologias.

$\mathrm{Na}$ visão dos alunos, o maior problema apresentado (para mais de $50 \%$ dos alunos), é a falta de equipamentos ou máquinas atualizadas. Com um percentual um pouco menor, encontra-se a proposta de ensino não adequada para o uso tecnológico e, só depois, a capacitação dos professores, ( para 11\% deles).

\section{O que é preciso para melhorar o ensino de Matemática com o uso das TIC?}

Para a equipe diretiva é preciso capacitar os professores, possuir uma estrutura adequada para as tecnologias, utilizar software e projetos referentes a matéria e a as redes sociais.

Para o corpo docente é necessário capacitar os professores, equipamentos atualizados com programas instalados para o professor utilizar e uma proposta de ensino adequada que priorize a utilização das tecnologias.

Para os alunos é necessário software específico da disciplina, utilizar mais as redes sociais, trabalhar com o excel, utilizar os notebooks na sala de aula, liberar o wi-fi para pesquisas e trabalhos na escola.

Ao comparar as sugestões vindas dos três grupos pesquisados percebe-se que é necessário um aperfeiçoamento por parte dos professores, equipamentos que permitam o uso das TIC's na sala de aula e uma proposta de ensino diferenciada. 


\section{Conclusões}

Os resultados encontrados neste artigo são muito semelhantes à pesquisa realizada por Löbler et al (2013), ao afirmar que a interação entre as TIC's e os alunos é algo positivo para o ensino, mas que existem alguns problemas nos recursos tecnológicos, na infraestrutura e na formação continuada dos professores. Foi possível verificar que a escola possui equipamentos tecnológicos, mas ainda sem a instalação de softwares adequados e sem um suporte técnico necessário. Além disso, os professores ainda não contam com a capacitação necessária para utilizarem todo o potencial disponibilizado pelas TIC's.

Todavia, a partir das intervenções realizadas nesta pesquisa, algumas modificações passaram a ocorrer no ambiente escolar. Os notebooks novos, que ainda não estavam em uso, passaram a ser utilizados pelos alunos e professores, e foi instalada a rede sem fio para acesso a internet, para que pudesse ser realizado este trabalho.

Para melhorar o funcionamento e o uso das TIC's na sala de aula, é necessário, a curto prazo, ampliar a utilização de notebooks, das redes sociais e de softwares específico de matemática.

Como soluções a médio e longo prazo, sugere-se o estabelecimento de parcerias com universidades para que ocorram capacitações docentes e a integração dos professores com o estado da arte da utilização das TIC's em suas área de atuação.

O ensino não depende somente das tecnologias, mas elas podem servir como um motivador para a aprendizagem.

Um bom educador, deve sempre transformar e ressignificar o mundo, não simplesmente adaptando-se a ele, mas intervindo na realidade e mantendo esperança na mudança e na melhoria, conforme afirma Freire (2014).

\section{Referências}

ALMEIDA, Maria Elisabeth. Educação e tecnologias no Brasil e em Portugal em três momentos de suas histórias. Educação, Formação \& Tecnologias. 2008. p.23-36.

BASTOS, Maria Afonso e RAMOS, Maria Altina. Tecnologias e competências de pensamento na aprendizagem da Língua Estrangeira - Inglês. Revista eCurriculum. 2005. p.589-609.

BELLONI, Maria Luiza. O que é mídia-educação. Campinas, SP: Autores Associados. 2005

BELLONI, Maria Luiza. Educação a distância. Campinas, SP: Autores Associados. 2009.

BRASIL. Ministério da Educação. Ciências da Natureza, Matemática e suas Tecnologias. In: S. d. Ministério da Educação, Orientações curriculares para o Ensino Médio (pp. 69-98). Brasília, 2008.

BRASIL, Ministério da Educação. Diretrizes Curriculares Nacionais para o Ensino Médio. In: Diretrizes Curriculares Nacionais da Educação Básica. Brasília: ISBN. 2013. p.145-201 
COUTINHO, Clara Pereira. Metodologia de Investigação em Ciências Sociais e Humanas: Teoria e Prática. Coimbra: Almedina. 2013

DOWBOR, Ladislau. Tecnologia do conhecimento: os desafios da educação. Rio de Janeiro: Vozes. 201

FREIRE, Paulo. Pedagogia dos sonhos possíveis. São Paulo: Paz e terra. 2014.

GIL, Antônio Carlos. Como elaborar projetos de pesquisa. São Paulo, Atlas, 2010

LÖBLER, M. L., PRETTO, D., BOLZAN, L. M., Percepção dos Alunos a respeito da Inclusão de Tecnologias Digitais no Ensino Público. Rio Grande do Sul. Revista de Novas Tecnologias na Educação, v.11, n.3. 2013.

MASETTO, Marcos T. Mediação pedagógica e o uso da tecnologia. In: J. M. Moran, M. T. Masseto, \& M. A. Behrens, Novas tecnologias e mediação pedagógica (pp. 133-173). Campinas, SP: Papirus. 2000. p.133-173

MORAN, José. Manuel. A educação que desejamos: novos desafios e como chegar lá. Campinas: Papirus. 2007.

MORAN, José. Manuel. e outros. Mediação pedagógica e o uso da tecnologia. Campinas, SP: Papirus. 2011.

NUNES, Marcelo Pereira e GIRAFFA, Lucia. A Educação na Ecologia Digital. Technical Reports Series. 2003.

PACIEVITCH, Thais. (s.d.). Tecnologia da Informação e Educação. Disponível em Info Escola: http://www.infoescola.com/informatica/tecnologia-da-informacaoe-comunicacao. Acesso em 04/02/2014.

PEREIRA, Maria da Graça D e SILVA, Bento Duarte. A relação dos jovens com as TIC e o factor divisão digital na aprendizagem. Actas do X Congresso Internacional Galego-Português de Psicopedagogia. Braga. 2009. p.5408-5431.

PERRENOUD, Philippe e outros. As competências para ensinar no século XXI: a formação dos professores e o desafio da avaliação. Porto Alegre: Artmed Editora. 2002.

SANTOS, Edmía Oliveira dos. Formação de professores e cibercultura: novas práticas curriculares na educação presencial e a distância. Revista da FAEEBA- Educação e Contemporaneidade. 2002. p. 113-122.

SANTOS, Gladis Leal dos. Sobre mídias e tecnologias. disponível em Educação, tecnologia e algo mais.: Disponível em: https://gladislsantosbr.wordpress.com/2008/03/02/sobre-midias-e-tecnologias. Acesso em 15/05/2015.

SEABRA, Cristina Marcela. As redes sociais e a aprendizagem de matemática baseada na resolução de problemas. Disponível em Repositorium Uminho: repositorium.sdum.uminho.pt/handle/1822/25346. Acesso em 14/05/2015. 
SIGNFICADO DE TECNOLOGIA. (s.d.). Disponível em Signficados.com.br: http://www.significados.com.br/tecnologia-2. Acesso em 17/05/2015.

SILVA, Bento e outros. Reflexões sobre a tecnologia Educativa. Actas do IV Congresso Galaico-Português de Psicopedagogia. Braga: Universidade do Minho. 1998. p.238-247

SILVA, Marise Borba. Recursos Midiáticos para o Ensino. Blumenau, Santa Catarina, Brasil: IADE. 2010.

TEIXEIRA, Paula Maciel. O uso de computadores em salas de aula do 20 ano no ensino fundamental de escolas públicas, municipais e estaduais de São Francisco de Paula- RS. São Francisco de Paula: UERGS: Unidadade de São Francisco de Paula. Curso de Pedagogia. 2013.

VALENTE, José. Armando. O computador na sociedade do conhecimento. In: J. A. Valente, Análise dos diferentes tipos de softwares usados na educação. Brasília: Estação Palavra. 1999. p.71-85

VALENTE, José. Armando. (s.d.). As tecnologias digitais e os diferentes letramentos. Pátio Revista Pedagógica.

WEBBER, Carine Geltrudes e outro. Tecnologias na educação: propostas para situações de colaboração e criativdiade em sala de aula. In: V. Villas-Boas, F. Miotto, \& J. A. Martins, Novas Metodologias para o Ensino Médio em Ciências, Matemática e Tecnologia . Brasília: ABENGE. 2011. p.33-41 